\title{
SÃO PAULO E SUAS MIGRAÇÕES NO FINAL DO SÉCULO 20
}

Rosana BaEninger

\footnotetext{
Resumo: Este artigo busca resgatar as tendências migratórias nacionais para o Estado de São Paulo nos anos 90, destacando a centralidade da Região Metropolitana de São Paulo. No âmbito intra-regional, são analisados os fluxos migratórios metrópole-interior, em especial nas áreas consolidadas como espaços ganhadores de população.

Palavras-chave: Migração. Redistribuição da população. Urbanização.
}

\begin{abstract}
This article seems to recover the national migratory trends for the State of São Paulo in 1990s, denoting the centrality of the São Paulo Metropolitan Area. In the intra-regional scope, the metropolis-interior migratory flows are analyzed, in special in the areas consolidated as spaces witch receive population. Key words: Migration. Redistribution of population. Urbanization.
\end{abstract}

$\mathrm{O}$ presente trabalho busca analisar o papel de São Paulo no contexto migratório nacional nos anos 90, bem como aprofundar aspectos da dinâmica intra-estadual.

As preocupações que permeiam o trabalho estão pautadas nas seguintes questões: houve a continuidade do processo de desconcentração populacional da metrópole de São Paulo? Qual foi o comportamento das áreas caracterizadas como de evasão populacional? Como se deu o crescimento das cidades e o crescimento da população segundo a morfologia da rede urbana paulista? Os pólos regionais continuaram sendo absorvedores de população?

As tendências apontadas a seguir indicam novos arranjos migratórios no Estado: há a consolidação de determinadas áreas; a expansão da migração para regiões fora das franjas metropolitanas; ao mesmo tempo, observa-se a redefinição de espaços da migração, tanto na metrópole de São Paulo quanto no interior. ${ }^{1}$ Essas evidências empí- ricas estimulam algumas interpretações teóricas que, sem abandonar a importância das transformações econômicas e suas relações com a dinâmica migratória e regional, consideram abordagens que possam ser complementares e mais voltadas para a sociologia contemporânea.

\section{ASPECTOS TEÓRICOS DA MIGRAÇÃO NAS ÚLTIMAS DÉCADAS}

As tendências gerais dos deslocamentos populacionais no Brasil ocorridos desde os anos 30 até a década de 70 estiveram ancoradas na enorme transferência de população do meio rural para o urbano, nas migrações com destino às fronteiras agrícolas, no fenômeno da metropolização e na acentuada concentração urbana.

Na vertente da migração rural-urbana, Singer (1973) contextualizou esses movimentos migratórios no bojo do processo de industrialização em curso, onde os desloca- 
mentos populacionais - com origem no rural e destino urbano representavam a força de trabalho necessária à etapa de acumulação capitalista. As áreas rurais estagnadas ou em processo de transformação contribuíam para "fatores de estagnação" ou "fatores de mudanças" impulsionadores de fluxos migratórios nos locais de origem, onde as "causas" e os "motivos" da migração eram resultantes das transformações econômicas globais da sociedade. Os excedentes populacionais do rural constituíam transferências populacionais para as cidades, com a incorporação desses contingentes no mercado de trabalho industrial em expansão.

Embora os movimentos migratórios rural-urbanos fossem a principal força redistributiva da população, principalmente nos anos 50 e 60, o panorama dos movimentos migratórios no Brasil foi se ampliando a partir de então, até mesmo pela nova etapa de desenvolvimento econômico que o país viria assistir (CANO, 1988; PACHECO; PATARRA, 1998; MARTINE, 1987). Segundo Martine e Camargo (1984), o cenário da distribuição espacial da população brasileira a partir dos anos 60 foi movido por forças centrífugas, com a expansão populacional (migrações inter-regionais) rumo às áreas de fronteiras, e por forças centrípetas, com a migração rural-urbana em direção às grandes cidades do Sudeste, particularmente para a Região Metropolitana de São Paulo.

Já nos anos 70, no bojo dessa bipolaridade, as forças de reforço à concentração (forças centrípetas) faziam-se notar, promovendo a emigração das áreas de fronteiras agrícolas em direção às cidades maiores (MARTINE, 1987). Nesse contexto, a urbanização nacional operavase em moldes cada vez mais concentradores, em um processo de distribuição da população que tendia a privilegiar os grandes centros urbanos do Sudeste.

A partir dos anos 80, essas forças redefinem-se com mais nitidez e pode-se compreender melhor as direções e os sentidos das migrações internas. As "forças centrífugas", resultantes da força de atração exercida pelas fronteiras agrícolas, já haviam acentuado sua perda de importância nos anos 70 (MARTINE, 1987), muito embora seus desdobramentos tenham ainda se refletido, nos anos 80 e início dos 90, nos movimentos migratórios. Já as "forças centrípetas", em especial a exercida pela metrópole de São Paulo, arrefeceram pós anos 80 , porém não desapareceram (BAENINGER, 1999). Compondo um movimento mais amplo de distribuição populacional, a Região Metropolitana de São Paulo - RMSP também passou a se destacar pela importância de seu volume emigratório em nível nacio- nal, emprestando recentes características ao processo de distribuição espacial da população e redefinindo alguns aspectos da migração interna, ao mesmo tempo em que ainda se mantém como o maior centro de recepção migratória.

As migrações internas assumem, nesse contexto, maior complexidade, particularmente pelo predomínio das migrações entre áreas urbanas; ou seja, movimentos migratórios constitutivos e elemento fundamental na configuração de novas espacialidades. Portanto, o entendimento do processo de reorganização da população no espaço desloca-se do eixo de análise via migração ruralurbana, que é a força motriz das análises centrípetas.

Nas últimas décadas, as migrações internas no Brasil foram marcadas por alterações expressivas em sua dinâmica - e estas refletem-se nas novas especificidades e tendências do processo de distribuição espacial da população. Ao lado dos fluxos tradicionais, também passam a sobressair-se como elementos explicativos e determinantes do fenômeno migratório: outras direções (movimentos de curta distância, movimentos de retorno, movimentos intra-regionais) e novas dimensões da migração - em particular a espacial.

As tendências recentes dos movimentos migratórios no Brasil suscitaram análises interpretativas enriquecedoras do debate atual. As transformações ocorridas no fenômeno migratório poderiam estar apontando: a configuração de um novo padrão migratório brasileiro (BRITO, 1997); o resultado das transformações ocorridas na sociedade e em sua dinâmica econômica no mesmo período (PACHECO; PATARRA, 1998); variações de um mesmo processo historicamente referenciado no tempo e no espaço (CUNHA, 1999); a desconcentração da população frente à desconcentração econômica (MATOS, 1995); a expansão dos espaços da migração (BAENINGER, 1999).

Mesmo com diferentes maneiras de interpretar o fenômeno, essas análises indicam, de modo geral, a partir dos anos 80, as evidências e características apontadas anteriormente: inflexão no ritmo de crescimento metropolitano, aumento nas migrações de curta distância, importância do fluxo de retorno, esgotamento dos deslocamentos para as fronteiras agrícolas, diminuição no ímpeto das migrações inter-regionais.

Os anos 90 foram ainda mais desafiadores em termos de interpretações teóricas, particularmente em relação às análises pautadas na interiorização da indústria, uma vez que esse processo vem perdendo fôlego desde meados dos 80 .

Se, de um lado, os anos 80 e 90 assistiram a intensificação e consolidação de tendências já observadas nos anos 70, deve-se, contudo, considerar que, a partir de então, 
esses fenômenos estiveram contextualizados em tempos, momentos e espaços inseridos em uma outra sociedade: na sociedade de risco (BECK, 1992) ou na alta modernidade (GIDDENS, 1991). A compreensão dos fenômenos urbanos, em especial as novas formas de mobilidade espacial da população, passam por dimensões que, mesmo como reflexos de reestruturações na economia, compõem um novo mosaico das interações sociais.

A articulação de processos locais ao âmbito regional e global promove "mecanismos de desencaixe" da sociedade (GIDDENS, 1991), com reflexos nos processos de urbanização e de redistribuição espacial da população nos variados contextos regionais. As novas territorialidades, por sua vez, aceleram seu processo de emergência na sociedade contemporânea, onde os riscos são compartilhados (OJIMA, 2003).

Nesse novo cenário, as novas territorialidades, que abrangem municípios diferenciados, estão imersas em um conjunto de "sistemas peritos" da sociedade (GIDDENS, 1991) - dentre os quais se destaca a facilidade de transportes -, contribuindo para a formação, a institucionalização e para os desafios da gestão desses espaços, tanto em termos das migrações e dos deslocamentos populacionais quanto das políticas sociais. O aumento da migração intrametropolitana e intra-regional é também uma resposta aos espaços compartilhados da sociedade de risco e indicam a necessidade de arranjos institucionais que contemplem essas novas territorialidades.

O aprofundamento futuro dessas interpretações poderá contribuir para o entendimento do fenômeno migratório em São Paulo, bem como para a compreensão da relação entre migração e urbanização nos espaços metropolitanos e interioranos.

\section{O PÓLO NACIONAL DE RECEPÇÃO MIGRATÓRIA: SÃO PAULO}

As tendências da migração nacional nas últimas décadas vêm indicando oscilações do volume migratório que se dirige a São Paulo. À intensa migração interestadual dos anos 70 (3,2 milhões de pessoas) seguiu-se uma redução na década de 80 (2,6 milhões). Isso parecia indicar que essa tendência continuaria para os anos 90; no entanto, nesse último período as migrações interestaduais para São Paulo voltaram aos patamares dos anos 70 (3,2 milhões de migrantes). ${ }^{2}$

Contudo, a outra face do fenômeno migratório estadual é marcada pela emigração de São Paulo - tendência que vem se mantendo constante a partir dos anos 80: de 1,3 milhões, nos 70, para 1,8 milhões, nos 90 .

Desse modo, considerando-se a "eficiência" do Estado de São Paulo na retenção da migração, observa-se que, nos anos 70, este figurava no contexto interestadual como área de média absorção migratória (IEM de 0,43), com um ganho líquido populacional de quase 2 milhões de pessoas. Já no período 1981-1991, passava para área de baixa absorção migratória (IEM de 0,28), decrescendo seu saldo migratório para 1,2 milhão de pessoas. No período 1990-2000, manteve essa baixa capacidade de retenção da migração, com o mesmo IEM $(0,29)$ registrado na década anterior, porém com um saldo migratório mais elevado de 1,5 milhão de pessoas. Destaca-se que, com relação aos anos 70, mesmo com volumes de migração semelhantes, os anos 90 registraram menor capacidade de retenção da população no Estado.

De fato, deve-se destacar que, dentre as características da migração interestadual para São Paulo, houve importante redução de seu volume absoluto dos anos 70 para os 80. Nos anos 70, a média anual era de 325.089 migrantes, baixando para 267.916, no período 1981-1991; para o período 1990-2000, este volume anual voltou a ser de 325.438 migrantes. Constata-se, portanto, que os anos 80 caracterizaram-se como o momento específico da tendência de declínio da imigração interestadual para São Paulo, e pode ter refletido os efeitos mais imediatos da desconcentração econômica, das novas economias regionais, das "ilhas de prosperidade" (PACHECO, 1998) que, juntamente com a forte crise econômica que se manifestava na metrópole de São Paulo, compuseram um movimento de população caracterizado tanto pela redução na imigração quanto pela forte emigração para fora de São Paulo.

O aumento da imigração nos anos 90 para o Estado de São Paulo - em especial para a RMSP - parece se dever menos a uma recuperação econômica da metrópole paulista (até pelo aumento da emigração nos 90), e mais, talvez, ao arrefecimento na capacidade de reter a população nas áreas de "origem" da migração. Essa retomada da imigração para São Paulo pode trazer à tona a discussão da reconcentração da migração em São Paulo. De fato, por um lado, em termos de migração de longa distância, parece que São Paulo mantém essa centralidade dos destinos migratórios; por outro, nesse mesmo movimento está presente um forte componente de retorno que transforma espaços migratórios anteriormente consolidados, como a RMSP, em áreas de intensas entradas e saídas de contingentes populacionais. 
Apesar da crise econômica, São Paulo continuou sendo o maior pólo de recepção da migração, bem como o “coração da economia nacional”. Portanto, no imaginário migratório - principalmente para os migrantes de áreas menos desenvolvidas - essa área continuará fazendo parte da geografia mental da população (VAINER, 1991). Talvez a relação migração/industrialização não seja tão nítida e direta como nos anos 60 e 70, mas, para os movimentos interestaduais, permanece a forte e complexa relação migração/emprego e, certamente, as redes sociais constituem elementos importantes da manutenção de históricos fluxos migratórios para a metrópole.

$\mathrm{Na}$ estrutura migratória dos fluxos de chegada e saída de migrantes inter-regionais de e para o Estado de São Paulo (Tabela 1), nos anos 90, o Nordeste continuou liderando em volume, respondendo por $52,6 \%$ dos que entraram no Estado. O volume total da imigração dessa região, que era de 1,3 milhão de migrantes, no período 1981-1991, subiu para 1,7 milhão entre 1990 e 2000.

Dentre os Estados da Região Nordeste, destaca-se o incremento da imigração, vinda principalmente da Bahia (de um volume de 437 mil pessoas, nos anos 80, para 652 mil, nos 90), do Maranhão (de 32 mil para 63 mil migrantes, respectivamente) e do Piauí (de 79 mil para 109 mil pessoas). Pernambuco continuou ocupando o segundo maior fluxo de migrantes do Nordeste para o Estado de São Paulo, porém mantendo no mesmo patamar seu volume de emigração (de 322 mil, entre 1980 e 1991 para 331 mil, nos anos 90). Por outro lado, a emigração do Estado de São Paulo para os estados nordestinos também aumentou: de 509 mil emigrantes, nos anos 80, para 690 mil, entre 1990 e 2000; para a Bahia, a emigração, que foi de 147 mil pessoas, na década de 80, passou para 223 mil, nos anos 90. Nas trocas líquidas populacionais, no entanto, São Paulo aumentou seu ganho com o Nordeste, de 834 mil pessoas para 982 mil, de uma para outra década; com a Bahia, nas trocas populacionais, São Paulo chegou a obter um ganho de 428 mil pessoas contra 289 mil, dos anos 80 .

Essa elevação no ganho populacional para o Estado de São Paulo, advinda das trocas migratórias, ocorreu também com os Estados da Região Norte. Ainda nos anos 80, São Paulo registrou uma emigração para essa região de cerca de 58 mil pessoas, como reflexo das possibilidades de expansão da fronteira agrícola e do garimpo, sendo o volume de entrada para o Estado praticamente o mesmo. Já nos anos 90, a emigração para os Estados da Região Norte em seu conjunto decresceu (49 mil migrantes), embora para o Estado do Pará possa-se observar um ligeiro aumento em seu volume (de 13 mil pessoas para 15 mil), o que resultou em um ganho populacional da ordem

TABELA 1

Volumes de Imigração e Emigração Interestadual, segundo Regiões

Estado de São Paulo - 1981-2000

\begin{tabular}{|c|c|c|c|c|c|c|}
\hline \multirow{2}{*}{ Regiões } & \multicolumn{2}{|c|}{ Imigração } & \multicolumn{2}{|c|}{ Emigração } & \multicolumn{2}{|c|}{ Trocas Migratórias } \\
\hline & 1981-1991 & $1990-2000$ & 1981-1991 & $1990-2000$ & 1981-1991 & $1990-2000$ \\
\hline BRASIL (1) & 2.679 .162 & 3.177 .676 & 1.494 .933 & 1.789 .544 & 1.184 .229 & 1.388 .132 \\
\hline Norte & 58.715 & 58.444 & 58.742 & 49.295 & -27 & 9.149 \\
\hline Pará & 26.275 & 25.478 & 13.192 & 15.511 & 13.083 & 9.967 \\
\hline Nordeste & 1.343 .496 & 1.672 .649 & 509.433 & 689.908 & 834.063 & 982.741 \\
\hline Maranhão & 32.136 & 63.309 & 13.244 & 19.675 & 18.892 & 43.634 \\
\hline Piauí & 79.823 & 109.358 & 26.004 & 49.794 & 53.819 & 59.564 \\
\hline Pernambuco & 322.686 & 331.070 & 121.071 & 128.640 & 201.615 & 202.430 \\
\hline Bahia & 437.131 & 652.212 & 147.587 & 223.420 & 289.544 & 428.792 \\
\hline Sudeste & 619.793 & 530.765 & 424.912 & 521.039 & 194.881 & 9.726 \\
\hline Minas Gerais & 475.269 & 411.590 & 326.580 & 412.020 & 148.689 & -430 \\
\hline Sul & 493.407 & 406.346 & 287.240 & 344.090 & 206.167 & 62.256 \\
\hline Paraná & 440.281 & 347.388 & 222.365 & 262.129 & 217.916 & 85.259 \\
\hline Centro-Oeste & 163.751 & 168.242 & 214.606 & 185.212 & -50.855 & -16.970 \\
\hline Mato Grosso & 37.689 & 45.425 & 64.125 & 40886 & -26.436 & 4.539 \\
\hline
\end{tabular}

Fonte: IBGE. Censos Demográficos 1991 e 2000 (tabulações especiais, Nepo/Unicamp).

(1) Exclui país estrangeiro. 
de 9 mil pessoas com origem na Região Norte para o Estado de São Paulo.

Considerando outra área de fronteira agrícola - a Região Centro-Oeste - a tendência a maior emigração para seus estados do que a imigração para São Paulo ainda permaneceu nos anos 90, embora o volume de emigrantes tenha apresentado uma diminuição: de 214 mil, no período 1980-1991, para 185 mil migrantes, nos anos 90 - o que resultou na manutenção da perda populacional de São Paulo para o Centro-Oeste em seu conjunto. Deve-se mencionar, contudo, que com o Estado do Mato Grosso, São Paulo reverteu a tendência de perda de população, de uma para outra década, passando a registrar um ganho populacional positivo; parte desse volume de imigração para São Paulo é composto por um movimento de retorno de migrantes que para lá se deslocaram em décadas passadas.

Foi com os Estados do Sudeste - em especial com Minas Gerais - que o Estado de São Paulo refletiu a expansão dos espaços da migração no Brasil: passou a registrar uma perda populacional nos anos 90. Embora o volume de entrada de mineiros constitua o segundo maior fluxo da migração para São Paulo, em torno de 410 mil pessoas, entre 1990 e 2000 (era de 475 mil, nos anos 80), a emigração em direção a esse Estado elevou-se, de 326 mil emigrantes para 412 mil, entre 1980-1991 e 1990-2000.

Com a Região Sul, embora o movimento de imigração tenha diminuído (de 440 mil pessoas para 347 mil) e o volume de emigração aumentado ligeiramente (de $222 \mathrm{mil}$ pessoas para $262 \mathrm{mil}$ ), os ganhos populacionais para São Paulo mantiveram-se, mesmo que em volume bem menor (de 217 mil pessoas para 85 mil).

Ou seja, a imigração vinda de Minas Gerais e Paraná ainda representam volumes expressivos de migrantes para o Estado de São Paulo. O que se constata, entretanto, é que o movimento emigratório foi bem mais acentuado, sobretudo para Minas Gerais. Em estudos anteriores sobre os anos 80, apontava-se uma tendência de menor migração para São Paulo oriundas desses estados. Na verdade, São Paulo continuará sendo o maior pólo de recepção migratória no país, ao mesmo tempo em que se assiste a expressiva emigração desta área para localidades específicas.

Os movimentos migratórios de e para São Paulo, segundo as Grandes Regiões, no período 1990-2000 indicaram:

- aumento da atração migratória do Estado com relação à Região Norte;

- incremento no volume de imigração vinda da Região Nordeste e da emigração de São Paulo para lá. Assim, São
Paulo volta a ser uma área de média absorção migratória com relação ao Nordeste;

- inversão da tendência do movimento migratório com Minas Gerais;

- manutenção da tendência de evasão populacional para o Sul, em especial para o Paraná, porém ainda mantendo ganhos populacionais com os Estados dessa região;

- com o Centro-Oeste, ainda manteve perdas populacionais, embora note-se a recuperação migratória com o Estado de Mato Grosso.

No cenário da migração brasileira, o Estado de São Paulo, no período 1990-2000, continuou recebendo mais da metade da emigração que saiu do Nordeste e até mesmo do Sul. Por outro lado, também continuou respondendo pelos maiores volumes de pessoas que chegaram a essas mesmas regiões. No entanto, a potencialidade migratória do Estado diminuiu com relação a Região Sul e Sudeste, aumentou com o Nordeste e Norte, e apontou essa mesma tendência com relação à Região Centro-Oeste.

Considerando o movimento emigratório do Estado de São Paulo, os anos 80 caracterizaram-se como a "década do retorno", quando 45,0\% dos migrantes que deixaram São Paulo estavam voltando aos seus Estados de nascimento. Nos anos 90, essa proporção foi semelhante, indicando que se trata de um fenômeno de longa duração e não apenas circunscrito a uma década. Esse refluxo populacional envolveu 669.781 pessoas no período 1981 1991, das quais quase a metade (319.340 migrantes) retornaram aos Estados nordestinos. No período 19902000, o retorno com origem em São Paulo alcançou 807.401 pessoas, sendo 427.524 para o Nordeste $(52,9 \%$ do total da emigração).

A emigração de São Paulo para Minas Gerais teve forte componente de retorno (45\%), bem como para o Paraná (39\%). Nesses dois casos, a redinamização recente de determinados espaços urbano-regionais serviu não só para diminuir a emigração dessas áreas para São Paulo, como também passaram a atrair um fluxo de retorno.

Para as Regiões Norte e Centro-Oeste, foram registradas as menores proporções e volumes de retornos. Para o Centro-Oeste, esse refluxo foi mais significativo em função da proximidade geográfica, e mesmo do bom desempenho econômico regional nesse período (GUIMARÃES; LEME, 1997) - tanto que São Paulo continuou perdendo população para essa região ainda nos anos 90, como já foi mostrado anteriormente. 
As direções e sentidos da imigração - e, particularmente, da emigração do Estado de São Paulo - comportam explicações distintas. Assim, no processo migratório interestadual paulista configuram-se, pelo menos, quatro situações:

- absorção de população vinda do esgotamento da fronteira agrícola do Norte;

- emigração do Estado de São Paulo (fluxos para o Nordeste);

- continuidade da imigração Nordeste $\rightarrow$ São Paulo, principalmente pelas redes migratórias pré-estabelecidas;

- fortalecimento da desconcentração migratória a partir de São Paulo em direção às áreas que registraram desdobramentos no processo de desconcentração industrial e agroindustrial do país (Minas Gerais, Rio Grande do Sul, Mato Grosso do Sul e Goiás).

Portanto, de um lado, São Paulo expandiu seus espaços de migração - sobretudo com a porção Centro-Leste e Sul do país, áreas onde os efeitos multiplicadores advindos da desconcentração foram mais acentuados - e, de outro lado, reforçou seu caráter de pólo nacional com as Regiões Nordeste e Norte.

\section{Redistribuição da População no Contexto Paulista}

O Estado passou de uma taxa de crescimento de 3,5\% a.a. nos anos 70 para $2,12 \%$ no período $1980 / 91$, chegando a 1,8\% a.a. nos anos 90 (Tabela 2). O menor crescimento da Região Metropolitana de São Paulo (1,9\% a.a., no período 1980/91 contra 4,5\% a.a. na década anterior e 1, 6\% a.a. 1991 e 2000) refletiu fortemente na taxa estadual.

A capital do Estado (ou seja, o Município de São Paulo) registrou um decréscimo considerável em sua taxa de crescimento da população total, passando de 3,7\% a.a., nos anos 70, para $0,87 \%$ a.a., nos anos 90 . O interior manteve mais ou menos estável sua taxa de crescimento: $2,6 \%$ a.a. em 1970/80 e 2,4\% a.a. no período 1980/91, baixando para $1,9 \%$ entre 1991 e 2000 .

Assim, a partir dos anos 80, tanto a Região Metropolitana de São Paulo quanto sua sede vêm apresentando taxas de crescimento populacional abaixo da média nacional (que foi de 1,93\% a.a., nos anos 80, e 1,6\% entre 1991 e 2000$)$ e estadual (2,1\% a.a. e 1,8\% a.a., respectivamente). Destaca-se, no entanto, que a periferia da área metropolitana de São Paulo apresentou ritmo de crescimento populacional mais elevado que a média do Estado e do interior: 3,20\% a.a., nos anos 80, e 2,8\% a.a., nos 90, indicando a intensa mobilidade intra-regional da população metropolitana.

O baixo crescimento populacional da área metropolitana de São Paulo evidenciou no período 1980/91, pela primeira vez na história do século 20 , um saldo migratório negativo de grande magnitude: cerca de 274 mil pessoas, sendo que o Município de São Paulo teve o maior peso nesse processo, chegando a registrar um saldo negativo de mais de 750 mil pessoas.

Entre 1991 e 2000, o saldo migratório permaneceu negativo para a cidade de São Paulo: 457 mil pessoas (Tabela 3). Nesse sentido, reforçando uma incipiente tendência anterior de "perda" de população, a Região Metropolitana de São Paulo - e, particularmente, a cidade de São Paulo - teria se transformado agora em área de circulação para uma parcela significativa da população migrante. O interior de São Paulo reforçou seu potencial de absorção migratória, passando de um saldo migratório positivo de 850 mil pessoas, nos anos 80 , para 1,1 milhão, nos anos 90 .

TABELA 2

População Total e Taxas de Crescimento Populacional

Estado de São Paulo, Região Metropolitana de São Paulo e Interior - 1970/2000

\begin{tabular}{|c|c|c|c|c|c|c|c|c|}
\hline \multirow[b]{2}{*}{ Área } & \multicolumn{5}{|c|}{ População Total } & \multicolumn{3}{|c|}{ Taxa de Crescimento (\% a.a.) } \\
\hline & 1970 & 1980 & 1991 & 1996 & 2000 & $\begin{array}{l}1970- \\
1980\end{array}$ & $\begin{array}{c}1980- \\
1991\end{array}$ & $\begin{array}{l}1991- \\
2000\end{array}$ \\
\hline Estado de São Paulo & 17.771 .948 & 25.040 .712 & 31.436 .273 & 34.407 .358 & 37.035 .456 & 3,49 & 2,13 & 1,78 \\
\hline RMSP & 8.139 .730 & 12.588 .725 & 15.416 .416 & 16.581 .933 & 17.833 .511 & 4,46 & 1,86 & 1,63 \\
\hline Capital & 5.924 .615 & 8.493 .226 & 9.626 .894 & 9.839 .066 & 10.435 .546 & 3,67 & 1,15 & 0,87 \\
\hline Periferia & 2.215 .115 & 4.095 .499 & 5.789 .522 & 6.742 .867 & 7.397 .965 & 6,34 & 3,20 & 2,81 \\
\hline Interior de São Paulo & 9.632 .218 & 12.451 .987 & 16.019 .857 & 17.825 .425 & 19.201 .945 & 2,60 & 2,38 & 1,92 \\
\hline
\end{tabular}

Fonte: IBGE. Censos Demográficos 1970 a 2000; Contagem da População de 1996. 
TABELA 3

Saldos Migratórios

Estado de São Paulo, Região Metropolitana de São Paulo e Interior - 1980-2000

\begin{tabular}{lcc}
\hline Áreas & \multicolumn{2}{c}{ Saldos Migratórios } \\
\cline { 2 - 3 } & $1980-1991$ & $1991-2000$ \\
\hline Estado de São Paulo & $\mathbf{5 5 6 . 4 2 4}$ & 1.326 .987 \\
RMSP & -290.455 & 219.051 \\
Município de São Paulo & -754.358 & -457.416 \\
Outros Municípios da RMSP & 463.903 & 677.007 \\
Interior & 846.879 & 1.107 .36 \\
\hline
\end{tabular}

Fonte: Fundação Seade (2002).

Esse processo de desconcentração populacional da área metropolitana de São Paulo está, em parte, associado à crise econômica dos anos 80 e à recessão econômica dos anos 90. Pode-se dizer que até os anos 80 , o processo de desconcentração da indústria de São Paulo em direção a outros estados e para o interior (NEGRI; PACHECO, 1993) foi acompanhado, embora com defasagem temporal - pois a desconcentração econômica foi mais contundente nos anos 70 -, de importantes fluxos migratórios na mesma direção. A partir dos anos 90, o processo de reestruturação produtiva tem mudado o perfil da indústria brasileira, com a retomada do maior peso relativo do Estado de São Paulo na distribuição da indústria de transformação nacional. Assim, em que pese a enorme alteração na "dimensão espacial do desenvolvimento brasileiro", o Estado de São Paulo diversificou e modernizou sua indústria de transformação, permanecendo na posição de centro dinâmico do país. ${ }^{3}$

Na verdade, a "condição pós-moderna" (HARVEY, 1992) que busca a metrópole paulista tenderá a gerar, cada vez mais, um enorme excedente populacional sem que ocorra uma perda de dinamismo econômico da região; a redefinição de seu papel no cenário nacional e a competitividade entre metrópoles do mundo globalizado fará com que esta área reafirme seu caráter de centro decisório do país, especialmente em termos financeiros, tornando-se apenas área de circulação para a população migrante.

Essa reestruturação produtiva implica também na competitividade entre os espaços urbanos para sua inserção nessa dinâmica global; nesse esforço, Harvey (1992, p. 267) enfatiza que

a produção ativa de lugares dotados de qualidades especiais se torna um trunfo na competição espacial entre as localidades, cidades, regiões e nações [...] criando uma atmosfera de lugar e tradição que aja como atrativo para o capital e para pessoas "do tipo certo" (isto é abastadas e influentes).

Nessa nova etapa de desenvolvimento econômico, as regiões mais dinâmicas estão "abertas" e absorvem os migrantes qualificados; que é minoria. As variadas e distintas modalidades de movimentos migratórios, envolvendo principalmente áreas urbanas, rompem com o paradigma explicativo da emigração como um dos efeitos sociais negativos resultantes do menor crescimento econômico e, sobretudo, da ausência de atividades industriais fortes. Na relação migração/dinâmica econômica, as cidades mais prósperas (em termos de inserção no mercado regional, nacional e internacional) tendem a registrar os maiores volumes de emigrantes, tanto na RMSP quanto no interior do Estado. Assim, os fatores de expulsão, para os migrantes de baixa renda, estariam nas áreas mais dinâmicas e os de atração nas de menor dinamismo. Contudo, essa interpretação só faz sentido se a dimensão espacial for considerada como elemento constitutivo do próprio processo migratório. As migrações intrametropolitanas, intra-regionais e da metrópole para o interior exemplificam essa formulação.

As mudanças no paradigma da indústria,${ }^{4}$ que se manifestam na crescente diminuição da absorção de mãode-obra, já revelam o deslocamento do eixo explicativo da migração via industrialização. Se nos anos 70, principalmente, os destinos migratórios apresentavam estreita relação com o dinamismo industrial das regiões do interior (incluindo-se o agroindustrial), agora as evidências empíricas apontam a necessidade de mudanças nas abordagens sobre as migrações - em particular no caso paulista.

\section{TENDÊNCIAS DAS MIGRAÇÕES PAULISTAS: METRÓPOLE E INTERIOR}

Considerando o destino da migração vinda de outros Estados para o Estado de São Paulo, torna-se importante indicar os espaços paulistas desse movimento (Tabela 4).

Em que pese o aumento das migrações interestaduais para o interior de São Paulo, com tendência crescente nos últimos 30 anos (de 1,1 milhão, nos anos 70, para 1,4 milhão nos anos 90), é notável a retomada da força da RMSP na recepção dessa imigração, nos anos 90. Entre os anos 70 e 80, a metrópole paulista vivenciou expressivo decréscimo da migração interestadual: de 2,2 milhões 
TABELA 4

Imigração Interestadual

Estado de São Paulo, Região Metropolitana de São Paulo e Interior - 1970-2000

\begin{tabular}{lccc}
\hline Regiões & $1970-1980$ & $1981-1991$ & $1990-2000$ \\
\hline Estado de São Paulo & 3.325 .468 & 2.734 .819 & 3.177 .676 \\
RMSP & 2.196 .560 & 1.566 .206 & 1.781 .151 \\
Interior & 1.128 .908 & 1.168 .613 & 1.396 .525 \\
\hline
\end{tabular}

Fonte: IBGE. Censos Demográficos 1980, 1991 e 2000 (tabulações especiais, Nepo/Unicamp).

de migrantes para 1,5 milhão, respectivamente, para retomar o incremento desse movimento nos anos 90 (1,8 milhão). Assim, do total do movimento interestadual para São Paulo, 56\% tiveram como destino a RMSP.

Ao longo das últimas décadas, o interior também vem se constituindo como espaço dessa migração, ao elevar sua participação na distribuição relativa da migração interestadual. De fato, nos anos 70, respondia por 33,9\% dos destinos da migração interestadual; nos anos 80 , passou para 42,7\%; e, nos 90, alcançou 43,9\% do total da migração interestadual para São Paulo.

Nesse contexto, as procedências das migrações interestaduais para os distintos espaços da migração em São Paulo marcam suas especificidades. A RMSP constitui o grande pólo de recepção da migração nordestina, uma vez que responde por $73,6 \%$ dos migrantes nordestinos que chegaram ao Estado de São Paulo. Já o interior caracteriza-se pelos fluxos advindos de Minas Gerais e Paraná. Contudo, no novo cenário das migrações interestaduais no Estado - principalmente com o aumento nos volumes da imigração interestadual para o interior - o crescimento dos fluxos com origem no Nordeste em direção a essa área já era apontado nos anos 80. Essa tendência ampliou-se nos anos 90, fortalecendo o "corredor da migração nordestina" no interior do Estado de São Paulo (BAENINGER, 1999). No período 19811991, o volume da imigração nordestina para o interior paulista era de 273 mil pessoas, elevando-se para 440 mil, entre 1990 e 2000; ou seja, respondia por $24,7 \%$ da migração interestadual, passando para $26 \%$, respectivamente.

No contexto intra-estadual, a pergunta que se coloca para as migrações nos anos 90 é: "houve continuidade no fluxo de saída de população da metrópole para o interior?"

Como espaço perdedor iniciado nos anos 70, a metrópole paulista marcou a inflexão em sua trajetória de forte absorção migratória. A partir de então, o interior passou a ganhar população vinda da RMSP. Apesar da retomada das migrações interestaduais para a RMSP, a tendência à desconcentração de população em direção ao interior permaneceu nos anos 90: entre 1995 e 2000, cerca de 468 mil pessoas deixaram a metrópole.

TABELA 5

Fluxo Migratório Intra-Estadual entre Metrópole e Interior Estado de São Paulo - 1995-2000

\begin{tabular}{|c|c|c|c|}
\hline Regiões de Governo & $\begin{array}{l}\text { Imigração Vinda } \\
\text { da RMSP }\end{array}$ & $\begin{array}{l}\text { Emigração com } \\
\text { Destino a RMSP }\end{array}$ & $\begin{array}{c}\text { Trocas } \\
\text { Migratórias }\end{array}$ \\
\hline Total & 468.295 & 172.132 & 296.163 \\
\hline Registro & 8.257 & 2.569 & 568.888 \\
\hline Santos & 60.188 & 18.824 & 41.364 \\
\hline Caraguatatuba & 10.791 & 2.574 & 8.217 \\
\hline Cruzeiro & 1.164 & 524 & 640 \\
\hline Guaratinguetá & 3.629 & 1.790 & 1.839 \\
\hline São José dos Campos & 18.179 & 6.225 & 11.954 \\
\hline Taubaté & 12.515 & 3.253 & 9.262 \\
\hline Avaré & 7.318 & 2.088 & 5.230 \\
\hline Botucatu & 6.562 & 1.096 & 5.466 \\
\hline Itapetininga & 13.117 & 3.195 & 9.922 \\
\hline Itapeva & 3.619 & 1.932 & 1.687 \\
\hline Sorocaba & 42.312 & 9.117 & 33.195 \\
\hline Bragança Paulista & 20.795 & 4.228 & 16.567 \\
\hline Campinas & 69.248 & 13.284 & 55.964 \\
\hline Jundiaí & 22.398 & 3.843 & 18.555 \\
\hline Limeira & 8.478 & 2.379 & 6.099 \\
\hline Piracicaba & 8.747 & 2.171 & 6.576 \\
\hline Rio Claro & 5.951 & 1.224 & 4.727 \\
\hline São João da Boa Vista & 7.907 & 2.033 & 5.874 \\
\hline Araraquara & 7.766 & 2.958 & 4.808 \\
\hline Barretos & 4.650 & 2.060 & 2.590 \\
\hline Franca & 4.611 & 2.058 & 2.553 \\
\hline Ribeirão Preto & 11.852 & 5.096 & 6.756 \\
\hline São Carlos & 7.897 & 1.666 & 6.231 \\
\hline São Joaquim da Barra & 866 & 423 & 443 \\
\hline Bauru & 11.750 & 3.509 & 8.241 \\
\hline Jaú & 3.826 & 1.013 & 2.813 \\
\hline Lins & 4.439 & 797 & 3.642 \\
\hline Catanduva & 4.257 & 1.582 & 2.675 \\
\hline Fernandópolis & 1.990 & 705 & 1.285 \\
\hline Jales & 3.603 & 1.545 & 2.058 \\
\hline São José do Rio Preto & 15.556 & 3.766 & 11.790 \\
\hline Votuporanga & 3.662 & 795 & 2.867 \\
\hline Andradina & 3.476 & 1.301 & 2.175 \\
\hline Araçatuba & 10.160 & 3.470 & 6.690 \\
\hline Adamantina & 3.686 & 1.211 & 2.475 \\
\hline Dracena & 2.569 & 1.248 & 1.321 \\
\hline Presidente Prudente & 9.712 & 4.316 & 5.396 \\
\hline Assis & 5.069 & 1.683 & 3.386 \\
\hline Marília & 8.219 & 2.736 & 5.483 \\
\hline Ourinhos & 4.928 & 1.534 & 3.394 \\
\hline Tupã & 2.576 & 1.043 & 1.533 \\
\hline Ignorado São Paulo & - & 43.268 & - \\
\hline
\end{tabular}

Fonte: IBGE. Censo Demográfico 2000 (tabulações especiais, Nepo/Unicamp). 
O panorama das migrações metrópole-interior em São Paulo reforça a importância dos pólos regionais na expansão das migrações no Estado (Tabela 5). Os pólos econômico-populacionais, que em décadas passadas já registravam atração nessa migração metropolitana, continuaram a fazê-lo no período 1995-2000. A Região Metropolitana de Campinas continuou a canalizar o maior volume dessa emigração (cerca de 69 mil migrantes vindos da metrópole), seguida pelas Regiões de Governo (RG) de Santos (60 mil), Sorocaba (42 mil), São José dos Campos (18 mil), São José do Rio Preto (15 mil), Ribeirão Preto (11 mil), Bauru (11 mil), Araçatuba (10 mil) e Presidente Prudente (9 mil).

No final dos anos 90, outras regiões de recepção da migração metropolitana vieram somar-se a esses pólos - o que indicou a consolidação da expansão dos espaços de migração em São Paulo: RGs de Bragança Paulista (20 mil migrantes), Jundiaí (22 mil), Caraguatatuba (11 mil), Taubaté (12 mil) e Itapetininga (13 mil). Assim, torna-se necessário fazer a revisão desses antigos pólos regionais acima mencionados. Afinal, há outros espaços que também passam a absorver população e a desempenhar importante papel no processo de desconcentração da população, reforçando o fenômeno da interiorização da migração no Estado: os subcentros regionais da migração.

\section{TENDÊNCIAS DA MIGRAÇÃO E DA URBANIZAÇÃO NO INTERIOR}

Utilizando a morfologia e hierarquia da rede urbana (IPEA/IBGE/NESUR-UNICAMP, 2000) do Estado de São Paulo em 2000 apreende-se que:

- as metrópoles envolveram 67 municípios do Estado, o que corresponde a cerca de 22 milhões de habitantes;

- as aglomerações urbanas, totalizaram 48 municípios e 3,8 milhões de pessoas;

- os centros urbanos somaram 9 localidades e concentram 1,8 milhão de habitantes;

- além dessas espacialidades, outros 521 municípios - que perfazem mais de 8 milhões de pessoas - compuseram a rede urbana paulista, que integrou o dinamismo das demais regiões do Estado (Tabela 6).

Nota-se que, mesmo quando se adota outro recorte para a rede urbana paulista que não as regiões de governo, é possível apreender taxas positivas de crescimento de municípios situados fora das grandes concentrações urbanas. $\mathrm{Na}$ verdade, observa-se um gradiente no ritmo de crescimento das populações desses municípios não-metropolitanos: parte de um patamar de 1,3\% a.a. para os que tinham menos de 10 mil habitantes no período 1996-2000 e atinge 2,5\% a.a. na categoria 100 mil-300 mil habitantes, com li-

TABELA 6

População, segundo Rede Urbana (1)

Estado de São Paulo - 2000

\begin{tabular}{|c|c|c|c|c|c|}
\hline Rede Urbana & $\begin{array}{c}\text { Número } \\
\text { de } \\
\text { Municípios }\end{array}$ & $\begin{array}{l}\text { População Total } \\
(2000)\end{array}$ & $\begin{array}{c}\text { Distribuição } \\
\text { Relativa } \\
(\%)\end{array}$ & $\begin{array}{c}\text { Taxa de } \\
\text { Crescimento } \\
(1996-2000)\end{array}$ & $\begin{array}{c}\text { Grau de } \\
\text { Urbanização } \\
(2000)\end{array}$ \\
\hline Estado de São Paulo & 645 & 37.035 .456 & 100,00 & 2,02 & 93,41 \\
\hline Menos de 10 mil habitantes & 291 & 1.774 .458 & 4,79 & 1,34 & 74,99 \\
\hline De $10-20$ mil habitantes & 105 & 1.806 .455 & 4,88 & 1,48 & 78,41 \\
\hline De $20-50$ mil habitantes & 91 & 3.260 .919 & 8,80 & 1,73 & 86,91 \\
\hline De 50-100 mil habitantes & 31 & 2.620 .884 & 7,08 & 2,05 & 89,45 \\
\hline De $100-300$ mil habitantes & 3 & 340.121 & 0,92 & 2,48 & 90,35 \\
\hline Sub-Total & 521 & 9.802 .837 & 26,47 & 1,73 & 84,14 \\
\hline Metrópoles (SP, CPS, BS) & 67 & 21.657 .859 & 58,48 & 2,01 & 96,15 \\
\hline Núcleo & & 11.820 .017 & 31,92 & 1,39 & 94,58 \\
\hline Entorno & & 9.837 .842 & 26,56 & 2,78 & 98,03 \\
\hline Aglomerações Urbanas Não-Metropolitanas & 48 & 3.806 .402 & 10,28 & 2,37 & 94,94 \\
\hline Centros Urbanos & 9 & 1.768 .358 & 4,77 & 2,01 & 96,65 \\
\hline
\end{tabular}

Fonte: IBGE. Censo Demográfico 2000. 
geiras elevações nessa taxa de crescimento nas classes de tamanho subseqüentes. Essa mesma tendência pode ser verificada quanto ao grau de urbanização, de $75 \%$ a 90,3\%, nas respectivas categorias de tamanhos de municípios. Assim, apenas apresentaram crescimento os municípios com menos de 20 mil habitantes e não pertencentes a áreas metropolitanas e aglomerações urbanas. Isso ocorreu nos últimos cinco anos, a uma taxa abaixo da média estadual: $1,6 \%$ a.a. contra $2,0 \%$ a.a. - muito embora deva-se considerar a expressiva recuperação demográfica dessas localidades.

Adotando novamente as regiões de governo, é possível apreender outra especificidade do atual processo de urbanização em São Paulo, qual seja: o menor crescimento populacional das sedes regionais e o crescimento mais elevado de suas áreas no entorno - onde justamente predominam os municípios pequenos.

Enquanto o conjunto das sedes regionais do interior cresceu a 1,6\% a.a. no período 1991-1996, nas áreas de entorno essa taxa foi ligeiramente superior: 1,7\% a.a. Essa situação é distinta das décadas anteriores, quando, por exemplo, nos anos 70, os municípios-sede cresciam a 3,0\% a.a. e seus entornos $2,1 \%$ a.a. O crescimento desses entornos regionais implica um adensamento da rede urbana por todo o Estado. Seus efeitos podem ser verificados na reversão da tendência dos pequenos municípios, antes incapazes de reter sua população. Nessa nova realidade regional, a caracterização da rede urbana estadual não mais comporta agregar os municípios em faixas de tamanho, distantes de seu contexto regional.

De fato, o complexo conjunto de mudanças econômico-espaciais experimentados pelo interior paulista contribuiu para o fortalecimento das distintas economias regionais, favorecendo, por um lado, a dispersão populacional no Estado e, por outro, um rearranjo das formas de distribuição espacial da população no âmbito de cada região. Nesse contexto, são incorporados ao sistema urbano em expansão vários municípios pequenos e de porte intermediário. Ao mesmo tempo, as cidades de médio e grande portes vêm apresentando uma desaceleração em seus ritmos de crescimento populacional. Assim, a histórica rede urbana do interior redesenha-se em múltiplas formas.

Nos últimos 30 anos, a recuperação populacional do interior de São Paulo esteve ancorada em seu potencial de absorção migratória no âmbito do próprio Estado. Os saldos migratórios registrados pelas regiões de governo apontam a importância desses espaços no processo de redistribuição da população paulista (Tabela 7).
Nos anos 90, os núcleos regionais desempenharam um papel relevante no processo interno de redistribuição da população:

TABELA 7

Saldos Migratórios, segundo Regiões de Governo Estado de São Paulo - 1980-2000

\begin{tabular}{|c|c|c|c|c|}
\hline \multirow{2}{*}{ Regiões de Governo } & \multicolumn{2}{|c|}{ Núcleo } & \multicolumn{2}{|c|}{ Entorno } \\
\hline & $1980-1991$ & $1991-2000$ & $1980-1991$ & $1991-2000$ \\
\hline Registro & -2.247 & -2.538 & -10.766 & 5.130 \\
\hline Santos & -45.701 & -19.782 & 97.933 & 98.253 \\
\hline Caraguatatuba & 8.455 & 16.803 & 21.933 & 31.959 \\
\hline Cruzeiro & -2.065 & -3.123 & -4.582 & -63 \\
\hline Guaratinguetá & -1.694 & 711 & -4.867 & -1.305 \\
\hline São José dos Campos & 59.480 & 31.266 & 17.412 & 9.333 \\
\hline Taubaté & -3.587 & 11.682 & 15.438 & 13.959 \\
\hline Avaré & 3.630 & 8.433 & -15.152 & 621 \\
\hline Botucatu & 11.933 & 7.398 & 4.703 & 7.074 \\
\hline Itapetininga & 331 & 8.640 & 25.576 & 29.547 \\
\hline Itapeva & -1.941 & -1.179 & -23.547 & -18.531 \\
\hline Sorocaba & 40.921 & 63.522 & 78.228 & 71.343 \\
\hline Bragança Paulista & 7.071 & 11.988 & 25.333 & 33.669 \\
\hline Campinas & 30.825 & 28.521 & 256.554 & 221.211 \\
\hline Jundiaí & -25.381 & 4.383 & 64.261 & 60.192 \\
\hline Limeira & 19.767 & 16.020 & 23.889 & 17.982 \\
\hline Piracicaba & 22.290 & 19.845 & 11.369 & 9.882 \\
\hline Rio Claro & 7.250 & 18.171 & 4.794 & 11.043 \\
\hline São João da Boa Vista & 2.476 & 2.367 & 4.487 & 2.979 \\
\hline Ribeirão Preto & 44.855 & 30.789 & 34.276 & 25.884 \\
\hline Bauru & 35.427 & 27.126 & -13.807 & -18 \\
\hline Jaú & 5.688 & 9.468 & 7.915 & 6.426 \\
\hline Lins & -1.080 & 1.233 & -8.391 & -54 \\
\hline Catanduva & 6.397 & 6.525 & -9.157 & -288 \\
\hline Fernandópolis & -797 & 513 & -12.385 & -2.790 \\
\hline Jales & -713 & 1.233 & -19.045 & -3.717 \\
\hline São José do Rio Preto & 55.162 & 50.373 & -3.864 & 20.556 \\
\hline Votuporanga & 3.100 & 5.643 & -12.918 & -4.320 \\
\hline Andradina & -3.395 & -2.169 & -12.382 & 7.245 \\
\hline Araçatuba & 4.508 & 2.763 & -6.117 & 5.445 \\
\hline Adamantina & -5.414 & -1035 & -24.805 & -10.008 \\
\hline Dracena & -2.852 & -2.133 & -15.720 & -7.254 \\
\hline Presidente Prudente & -3.368 & 3.978 & 10.926 & -252 \\
\hline Assis & 3.485 & 4.176 & 6.217 & 504 \\
\hline Marília & 12.761 & 18.072 & -22.265 & 8.523 \\
\hline Ourinhos & 4.396 & 8.181 & -7.936 & -1242 \\
\hline Tupã & -5.702 & -279 & -15.393 & -5.940 \\
\hline Araraquara & 11.048 & 9.684 & 32.720 & 11.673 \\
\hline São Carlos & 16.380 & 18.900 & 9.041 & 9.999 \\
\hline Barretos & 8.495 & 1.179 & 21.031 & -99 \\
\hline Franca & 40.091 & 20.151 & -6.588 & 3.663 \\
\hline São Joaquim da Barra & 444 & 1.728 & -2.096 & 2.898 \\
\hline
\end{tabular}

Fonte: Fundação Seade (1993; 2002). 
- quer como pólo indutor de transferências populacionais para os municípios vizinhos, como no caso da região de Santos, onde esse processo aponta um saldo migratório negativo para a sede;

- quer como área canalizadora de expressivos fluxos migratórios inter-regionais, como são os casos das regiões do Oeste Paulista (Presidente Prudente, Ourinhos), que registram saldo migratório positivo na sede e negativo no entorno;

- ou ainda como centralidade principal da região, com fluxos que partem do entorno para a sede, como é o caso de Bauru.

Por outro lado, a nova configuração da urbanização paulista vem sendo marcada pela regionalização de espaços. Nesse caso, os municípios situados nos entornos regionais adensam a rede urbana, com crescimentos populacionais e saldos migratórios mais elevados que suas sedes, como nas regiões de Campinas, Santos, Sorocaba.

Apenas nove sedes regionais e quinze entornos regionais registraram saldos negativos no período 1991-2000: trata-se das regiões do extremo leste do Estado (Cruzeiro, Guaratinguetá) e do Oeste (Jales, Fernandópolis, etc). Assim, mesmo que com saldos negativos em decréscimos, os entornos dessas regiões e até alguns núcleos permanecem com sua tendência de perda populacional - muito embora essa emigração provavelmente ocorra entre regiões circunvizinhas e não mais em direção à metrópole.

Os pólos regionais continuaram a exibir os saldos migratórios mais elevados (regiões de Campinas, São José dos Campos, Ribeirão Preto, Sorocaba, São José do Rio Preto), mantendo a tendência de espraiamento populacional, ou seja, regiões ganhadoras fora das fronteiras metropolitanas da RMSP.

Nos anos 90, destacam-se também os elevados saldos migratórios das RGs de Caraguatatuba (no núcleo e no entorno), de Rio Claro (entorno), de Itapetininga (entorno), de Bragança Paulista (núcleo e entorno), de Marília (entorno), dentre outras.

Como já foi analisado em estudo anterior (BAENINGER, 2002), se por um lado assistiu-se à expansão dos espaços da migração em São Paulo - principalmente considerandose regiões como Marília, Assis, Jaú, Araçatuba, dentre outras -, por outro, houve a redefinição de algumas áreas anteriormente mencionadas como pólos regionais e que se destacaram por perda populacional em décadas anteriores, como Bauru (com saldos migratórios negativos no entorno) e Presidente Prudente.
A consolidação dos espaços da migração ocorreu nas regiões metropolitanas de: Campinas e da Baixada Santista. Na RG de São José do Rio Preto, de uma para outra década, a expansão dos espaços de migração no entorno traduziuse na reversão do saldo negativo para positivo. Portanto, os anos 90 parecem indicar uma diversidade de situações em termos de absorção migratória no Estado de São Paulo, inclusive com alguns retrocessos a tendências passadas.

\section{CONSIDERAÇÕES FINAIS}

O processo de redistribuição espacial da população e, em especial, a migração - marcou o final do século 20 em São Paulo. Enquanto o núcleo da RMSP consolidase como espaço perdedor de população, mantendo seu saldo migratório negativo dos anos 80 para os 90 , houve a redefinição de sua periferia, que, de saldo negativo nos anos 80 , passou a positivo nos 90 . Na verdade, além de reter os fluxos migratórios provenientes da cidade de São Paulo e acentuar a importância da migração intrametropolitana, essa periferia também passou a ter maior capacidade de retenção de migrantes vindos de outros Estados - mais até que a própria sede metropolitana. Portanto, a periferia da metrópole de São Paulo tornouse o novo espaço das migrações interestaduais, lugar antes reservado à capital do Estado.

Além disso, os anos 90 parecem indicar para o interior, uma diversidade de situações em termos de absorção migratória, inclusive com alguns retrocessos a tendências passadas. As regiões ganhadoras do interior do Estado articulam processos locais ao âmbito regional e global, promovendo "mecanismos de desencaixe" da sociedade (GIDDENS, 1991), com reflexos nos processos de urbanização e de redistribuição espacial da população nos variados contextos regionais.

As evidências empíricas apresentadas suscitam os seguintes pontos para a compreensão e aprofundamento dos estudos sobre movimentos migratórios que chegam, que partem e que se processam em São Paulo. Com relação à migração interestadual:

- se São Paulo mantiver os volumes elevados de nordestinos e, ao mesmo tempo, de saída de retorno, poderá se tornar uma área de rotatividade migratória - sobretudo a RMSP;

- o crescente afluxo de nordestinos para o interior pode representar maior possibilidade de retenção desses migrantes em relação à metrópole - com a expansão dos espaços da migração em relação a esse fluxo determinado; 
- o decréscimo na migração de Minas Gerais e Paraná e o aumento expressivo do retorno para esses estados contribui para que o Nordeste também passe a ter maior peso na migração do interior, dando novos contornos às especificidades da migração nessa área.

Em termos da migração intra-estadual:

- o processo de desconcentração populacional da metrópole em direção ao interior reforça o fenômeno do espraiamento populacional, ampliando áreas de recepção da migração no Estado;

- os pólos regionais mantiveram seus papéis de catalisadores da migração intra-estadual, ao mesmo tempo que continuaram a reter uma população que potencialmente migraria para a metrópole paulista;

- a dinâmica intra-regional vem ampliando os espaços da migração no Estado, aumentando os nexos entre os espaços econômicos e os espaços de migração.

Nesse sentido, o conceito de "urbano" definido por Villaça (1998, p. 330) como o

espaço estruturado pelas condições de deslocamento da força de trabalho enquanto tal e enquanto consumidora (deslocamentos casa-escola, casa-compras, casa-lazer e mesmo casa-trabalho

constitui também um caminho promissor para que as novas territorialidades urbanas sejam identificadas, bem como para apontar a importância da migração e das novas modalidades de deslocamentos populacionais (pendular, dupla residência, etc.) para a formação dessas territorialidades.

As evidências empíricas, as análises referentes às transformações econômicas e à dinâmica do mercado de trabalho, a questão da regionalização e da formação de novas territorialidades, as políticas sociais de transferência de renda, a manutenção dos fluxos migratórios em situação de crise econômica, a expansão dos espaços da migração, dentre outros, constituem aspectos a serem aprofundados para a compreensão das migrações e dos deslocamentos populacionais em São Paulo no século 21.

\section{NOTAS}

1. Considera-se interior, neste artigo, todos os municípios paulistas não integrantes da Região Metropolitana de São Paulo.

2. Perillo (2002) já indicava essa retomada da imigração para São Paulo nesse período baseando-se nos saldos migratórios da Fundação Seade: de 556 mil pessoas, nos anos 80, para 1,3 milhão, nos 90. A contagem de 1996 indicava tendência de aumento de alguns fluxos migratórios, como Bahia e Pará, mas não chegava a aumentar o volume total da imigração para o Estado (BAENINGER, 1999).

3. Veja-se os relatórios do Projeto: Desenvolvimento Tecnológico e Competitividade da Indústria Brasileira (NEGRI; PACHECO, 1993).

4. Veja-se, por exemplo, Benko e Lipietz (1994).

\section{REFERÊNCIAS BIBLIOGRÁFICAS}

BAENINGER, R. Expansão, redefinição ou consolidação dos espaços da migração em São Paulo?: análises a partir dos primeiros resultados do Censo 2000. In: ENCONTRO NACIONAL DE ESTUDOS POPULACIONAIS, 13., 2002, Ouro Preto. Anais... Belo Horizonte: Abep, 2002.

Região, Metrópole e Interior: espaços ganhadores e espaços perdedores nas migrações recentes no Brasil - 1980/1996. 1999. Tese (Doutorado) - Instituto de Filosofia e Ciências Humanas da Unicamp, Campinas, 1999.

BECK, U. Risk society: towards a new modernity. London: Sage Publications, 1992.

BENKO, G.; LIPIETZ, A. O novo debate regional: posições em confronto. In: ____. (Org.). As regiões ganhadoras - Distritos e redes: os novos paradigmas da geografia econômica. Oeiras: Celta Ed., 1994.

BRITO, F. População, espaço e economia numa perspectiva histórica: o caso brasileiro. 1997. Tese (Doutorado) - Faculdade de Ciências Econômicas, Cedeplar/UFMG, Belo Horizonte, 1997.

CANO, W. (Coord.). A interiorização do desenvolvimento econômico no Estado de São Paulo (1920-1980). São Paulo: Fundação Seade, 1988. (Coleção Economia Paulista, v.1-3).

CUNHA, J.M.P. (Coord.). Projeto Mobilidade e redistribuição espacial da população no Estado de São Paulo: características recentes, padrões e impactos no processo de urbanização. Campinas: Nepo/Unicamp, 1999. (Relatório Final).

GIDDENS, A. As conseqüências da modernidade. São Paulo: Ed. Unesp, 1991.

GUIMARÃES, E.N.; LEME, H.J.C. Caracterização histórica e configuração espacial da estrutura produtiva do Centro-Oeste. In: NEPO/UNICAMP. Redistribuição da população e meio ambiente: São Paulo e Centro-Oeste, 1. Campinas, 1997. p. 25-65. (Textos Nepo, 33).

HARVEY, D. A condição pós-moderna. São Paulo: Ed. Loyola, 1992.

IPEA/IBGE/NESUR-UNICAMP. Características e tendências da Rede Urbana no Brasil. Campinas: IE/Unicamp, 2000.

MARTINE, G. Migração e metropolização. São Paulo em Perspectiva, São Paulo, Fundação Seade, v. 1, n. 2, p. 28-31, jul./set. 1987.

MARTINE, G.; CAMARGO, L. Crescimento e distribuição da população brasileira: tendências recentes. Revista Brasileira de Estudos de População, Campinas, Abep, v. 1, n. 2, p. 99-143, jan./ dez. 1984.

MATOS, R.E.S. Dinâmica migratória e desconcentração da população na macrorregião de Belo Horizonte. 1995. Tese (Doutorado) - Cedeplar/UFMG, Belo Horizonte, 1995. 
NEGRI, B.; PACHECO, C.A. Mudança tecnológica e desenvolvimento regional nos anos 90: da interiorização do desenvolvimento à nova dimensão espacial da indústria paulista. Campinas: SCTDE/ FECAMP/IE-Unicamp, 1993. (Relatório Final - Projeto Desenvolvimento Tecnológico e Competitividade da Indústria Brasileira).

OJIMA, R. Instituições políticas e mudança ambiental: os novos arranjos institucionais na gestão de recursos hídricos e suas interfaces políticas. Dissertação (Mestrado) - Unicamp, Campinas, 2003.

PACHECO, C.A. Fragmentação da nação. Campinas: IE/Unicamp, 1998.

PACHECO, C.A.; PATARRA, N.L. Movimentos migratórios anos 80: novos padrões? In: ENCONTRO NACIONAL SOBRE MIGRAÇÃO, 1998. Anais... Curitiba: Abep/Ipardes, 1998.

Movimentos migratórios nos anos 80: novos padrões? In: ENCONTRO NACIONAL SOBRE MIGRAÇÃO, 1997, Curitiba. Anais... Curitiba: Ipardes, 1997.

PERILLO, S. Vinte anos de migração no Estado de São Paulo. In: ENCONTRO NACIONAL DE ESTUDOS POPULACIONAIS, 13., 2002, Ouro Preto. Anais... Belo Horizonte: Abep, 2002.
SINGER, P. Migrações internas: considerações teóricas sobre seu estudo. In: Brasiliense, 1973.

VAINER, C.B. Políticas migratórias no Brasil: origens, trajetórias e destinos. In: REUNIÃO DOS GRUPOS DE TRABALHO DA ASSOCIAÇÃO BRASILEIRA DE ESTUDOS POPULACIONAIS. Campinas: Nepo/Unicamp, dez. 1991.

VILLAÇA, F. Espaço intra-urbano no Brasil. São Paulo: Studio Nobel, 1998.

Rosana Baeninger: Doutora em Ciências Sociais, Professora Colaboradora do Departamento de Demografia do Instituto de Filosofia e Ciências Humanas da Unicamp, Pesquisadora do Núcleo de Estudos de População da Unicamp (baeninge@nepo.unicamp.br).

Artigo recebido em 17 de maio de 2005.

Aprovado em 6 de junho de 2005. 